so severe nor so frequent as those described by Drs. Garland and Sumner in adult patients. I have never seen ataxia, confusion, headache, dysarthria, or blurring of vision in my patients which I could attribute to sulthiame. Perhaps they are less suggestible than Dr. Garland's refractory adult epileptics. It is clearly time that control trials of sulthiame were carried out so that reliable indications of its uses and dangers may be established. I am sure that Drs. Garland and Sumner would agree.I am, etc.,

$$
\begin{aligned}
& \text { Department of Child Life T. T. S. INGRAM. } \\
& \text { and Health, } \\
& \text { - Edinburgh } 9 \text {. }
\end{aligned}
$$

\section{Chloroquine Neuromyopathy}

SIR,-Your leading article on chloroquine neuromyopathy (22 February, p. 452) prompts us to describe one case of this disorder which we investigated in 1962 but did not report owing to lack of conclusive evidence incriminating chloroquine.

The patient is a banker who developed rheumatoid arthritis in 1958 at the age of 28. In March 1961 therapy was begun with $250 \mathrm{mg}$. chloroquine phosphate per day. He improved a little and the dose was increased to $500 \mathrm{mg}$. per day in December 1961.

In February 1962 he noticed weakness of the thighs, and over the next four months he becam severely incapacitated. He was unable to walk steadily, he tripped easily, he required assistance from his arms when he rose from a chair and when he climbed or descended stairs, and he fell if he leaned forward. He noticed no weakness of the arms, but his handwriting had deteriorated.

By June 1962 he had a gross waddling gait. There was weakness of the flexors and extensors of the hips and knees, particularly of the glutei. Dorsiflexion of the feet was lost and plantar flexion was moderately weak. The affected muscles were not tender. There was no apparen weakness of the back, shoulders, arms, sternomastoids, or facial muscles. There was no fasciculation or obvious muscle wasting. The knee jerks were present and triceps jerks weak other tendon reflexes were absent. Sensation was normal. Some fingers were spindled, but movements were full and painless; other joint were clinically normal. There wa no clinical evidence of thyrotoxicosis. Ophthalmological examination showed clear corneae, no definite pigment changes at the macular areas, and a screening test showed no defect in the visual fields.

Investigations included : Normal temperature. W.B.C. 4,000/c.mm. Erythrocyte sedimentation rate 3 and $4 \mathrm{~mm}$. in 1 hour (Westergren). C.S.F.-normal dynamics and cell count; protein $68 \mathrm{mg} . / 100 \mathrm{ml}$; W.R. and colloidal gold test negative. Rose-Waaler test positive. Serum glutamic-oxaloacetic and glutamic-pyruvic transaminase normal. Urine creatinine $1.56 \mathrm{~g}$. and creatine $0.07 \mathrm{~g}$. per 24 hours. Lupus erythematosus cell test negative. Serum antinuclear factor present. Electrophoresis of serum proteins normal. $X$-ray of lumbar spine, pelvis, and chest normal ; hands showed early changes consisten with rheumatoid arthritis. Serum proteinbound iodine normal $(5.1 \mu \mathrm{g} . / 100 \mathrm{ml}$.).

Muscle biopsy from the right gluteus maximus showed "lymphorrhages" and occasional single degenerating muacle fibres which had lost their transverse striation and were being phagocytosed. The histological changes were considered nonspecific.

Electromyography showed widespread fibrillation and there was very little reduction of number of moror units. Many of the units were highly polyphasic. Conduction velocity in the lateral popliteal nerve was $39 \mathrm{~m}$. per second. This is at the lower limit of the normal range.
The investigations supported a diagnosis of acquired neuromyopathy. The E.M.G. pattern excluded primary muscular dystrophy. The diagnosis of "neuromyopathy" is suggested rather than simple toxic myopathy in view of the elevated C.S.F. protein and the nerve conductivity, which borders on the pathological range.

Chloroquine was discontinued when investigations began, and after four weeks' rest in bed there was slight im rovement in the affected muscles. The patient was then given a five weeks' course of corticotrophin (A.C.T.H. gel), beginning with 60 units twice daily for 10 days and gradually reducing the dose. At the end of five weeks muscle power was normal in the lower legs and feet, and much improved in the buttocks. Since January 1963, seven months after stopping chloroquine, his muscle power has been normal by sub;ective and objective assessment. Low-grade rheumatoid arthritis continues.

The time-relationships strongly suggest that this acquired neuromyopathy was due to chloroquine. Whether corticotrophin hastened recovery is doubtful ; the gradual clearance of chloroquine from the tissues may have been the important factor.-We are, etc.,

$$
\begin{aligned}
& \text { Western Infirmary, } \\
& \text { Glasgow. } \\
& \begin{array}{l}
\text { Northern General Hospital, } \\
\text { Edinburgh. }
\end{array}
\end{aligned}
$$

\section{Treatment of Status Epilepticus}

SIR,-We agree with the criticism of Dr E. M. R. Critchley and others (15 February, p. 437), but suggest that the use of depressant drugs may in some instances fail to control the fits or have serious side-effects. We have learned that depression of the central nervous system is unnecessary if the muscular activity of convulsions and the consequent hypoxia and metabohic and respiratory acidosis are prevented.

We have treated six patients in status epilepticus by curarization and controlled ventilation $^{12}$; all recovered completely. In each instance the fits had failed to respond to adequate anticonvulsant drugs, and in one case the frequent cerebral discharges of status epilepticus continued despite the following measures-a total dose of $3 \mathrm{~g}$. of thiopentone, deep ether or halothane anaesthesia, a single dose of $300 \mathrm{mg}$. of D-tubocurarine, and intravenous lyophilized urea.

The scheme of treatment was briefly as follows. After full curarization the patient was bronchoscoped to remove retained secretions and ventilated with air from an EastRadcliffe respirator. The curare was continued by intramuscular injections at hourly intervals. All patients had a metabolic acidosis requiring correction with intravenous sodium bicarbonate $(1.26 \mathrm{~g} . / 100 \mathrm{ml}$.) during the first 24 hours. Metabolism was maintained by tube feeding. ${ }^{3}$ Anticonvulsants were given in the dosage usually taken by the individual patients. In the curarized subject the fits could be monitored by an electroencephalograph or more conveniently by a pulse-rate monitor (since the fits produce tachycardia). After periods of five days to three weeks the fits ceased, and then curare and later controlled ventilation were discontinued.

This method of treatment is based on the hypothesis that if hypoxia and acidosis are corrected and metabolism maintained then status epilepticus will terminate spontaneously. We prefer this method to the use of large doses of depressant drugs leading to hypoxia, which of itself may perpetuate the cerebral arrhythmia.-We are, etc.,

JOHN S. ROBINSON.

Intensive Care Unit, E. SHERwOOd JONES. Whistcn Hospital, Rita McConN.

REFERENCES

1 Nisbet, H. I. A., Brit. med. F., 1959, 1, 95. Robinson, J. S., Brit. F. Anaesth., 1963, 35, 570.

\section{Abnormal Reaction to Disulfiram}

SIR,-I have recently observed a patient who developed bizarre visual hallucinations and agitation after receiving a test dose of half a pint of beer when taking disulfiram (" antabuse").

The patient was a 61-year-old man who was admitted to hospital on account of alcoholic addiction. $\mathrm{He}$ had been drinking excessively since 1959, but claimed that he rarely drank spirits. He had never had delirium tremens, but had on occasions been very tremulous, particularly in the mornings, and required a " morning cure." $\mathrm{He}$ had been eating poorly for two months before admission. The patient claimed he had been drinking up to 20 pints (11.4 litres) of strong ale per day.

The patient's general health on admission appeared to be fairly good, and there were no signs of organic damage due to alcohol. He was treated with parenteral vitamins and chlorpromazine, and recovered satisfactorily from a mild abstinence syndrome. Ten days after admission he was prescribed disulfiram $1 \mathrm{~g}$. for two days and $0.5 \mathrm{~g}$. daily afterwards. On the fourth day he was given one-half pint $(280 \mathrm{ml}$.) of beer and shortly after this he became very agitated and claimed that he saw bizarre coloured animals, half human, and that he also saw his wife, from whom he was separated. He was tremulous and had much difficulty in drinking a glass of water. Physically there was a mild tachycardia, flushing, and a moderate drop of blood-pressure. He improved spontaneously, and the whole reaction lasted approximately 40 minutes.

As I had not heard of a reaction like this with a test dose of alcohol, I contacted the manufacturers of disulfiram, who stated that they had never heard of such a reaction either. Though the patient is probably not a very reliable informant, I was in no doubt that he was visually hallucinated at the time. I wonder if any readers have come across a similar case ?-I am, etc.,

\section{St. Clement's Hospital, J. J. CockBurN.
London E.3.}

\section{Vitamin Therapy}

SIR,-I cannot believe that your expert contributor, answering Dr. E. B. Gordon's letter on vitamin therapy (29 February, p. 563), is serious in his suggestion that the use of high-dosage vitamin therapy in confusional states is empirical because of a "failure to state which vitamin to use for which confusional state."

Whatever the underlying biochemical derangement or pathological condition might be it is not unreasonable to suggest that the confusional state is a manifestation of a temporarily disordered cerebral metabolism. It is equally not unreasonable, provided that the supply of oxygen and glucose to the brain are unimpaired, to try and normalize metabolism by providing a sufficiently high level of those water-soluble vitamins which are known to be directly concerned in enzymatic 